\title{
Introduction to the Theory of Intersubjective Management
}

\author{
Vladimir A. Vittikh
}

Published online: 9 March 2014

(C) The Author(s) 2014. This article is published with open access at Springerlink.com

\begin{abstract}
The article proposes principles of construction of the theory of intersubjective management, based on postnonclassical scientific rationality and on concept of a free society, wherein the stake is made on non-violent means of decision-making oriented towards attainment of mutual understanding and consensus of heterogeneous actors who are in a problem situation and aimed to settle it. The actors not only cognize the world, but they create it. When occurs that they are bound by a common problem situation, the actors, possessing, by their nature, intersubjective mind, realize it differently, although they recognize simultaneously the necessity of any coordinated actions to control the situation. Following the conventional concept of truth by Poincaré, who interpreted the truth as the result of a convention, an agreement may be achieved to recognize certain subjective knowledge to be true for a restricted circle of actors. Such knowledge may be called intersubjective. In contrast to the bureaucratic theory that ignores individual qualities of the human being and sees it as a "cog" in the administrative mechanism, the theory of intersubjective management proceeds from the fact that the reserves of management efficiency rise should be sought not in the bureaucratic machine modernization, but in the human being, in every person, in the use of his intellectual and volitional resources.
\end{abstract}

Keywords Intersubjective management - Postnonclassical scientific rationality . Non-violent management $\cdot$ Mutual understanding and consensus of heterogeneous actors · Problem situations settlement - Use of human being's intellectual and volitional resources

\footnotetext{
V. A. Vittikh $(\varangle)$

Institute for the Control of Complex Systems of Russian Academy of Sciences, 61, Sadovaya Street, 443020 Samara, Russian Federation

e-mail:vav1940@gmail.com
} 


\section{Introduction}

The 20th century may be named the century of bureaucracy, since whole states, large projects (atomic project, space project etc), industrial enterprises, institutions (schools, universities etc), even small companies, as a rule, have been managed (and are still being managed) at the basis of "Ideal Bureaucracy" principles, formulated by Weber at the beginning of the past century (the term of management corresponds herein to the classical meaning thereof) (Johnson et al. 1967). Nevertheless, the shortcomings of this form of management process organization become apparent in the second half of the century. So, for example, the work (Shepard 1965) noted that "the bureaucratic structures are designed for the only purpose to exercise the actions which are amenable to be programmed in any stable and predicted surrounding conditions. However, the surrounding conditions become more and more volatile and rapidly changing. Now, the necessity has occurred to create the organizations of such a type which would allow adapting themselves quickly to any changing conditions; it is necessary to look for such structures, with the help of which people can be organized for a non-programmable innovatory activity".

Reforms of bureaucratic mechanisms has started but they don't give any marked changes for the better in the sense of management systems perfection, in so far as they haven't practically touched the two basic principles of the bureaucracy: rigid hierarchy of the power and ignoring of individual qualities of the organization's employees; they reduce a human being into a "cog" in the bureaucratic machine. "Mechanistic nature" and "impersonality" are perhaps the most characteristic features of the majority of existing management systems, which, by this cause, don't satisfy the more and more increasing practical needs in the contemporary open and dynamic world. "We need a more humanistic theory of organization",-_rightly believed (Shepard 1965). But what are the principles such a theory is to be constructed on? To answer this question, the present monograph proposes to develop the theory of intersubjective management, which is opposed to the bureaucratic theory and proceeds from the idea that the reserves of management efficiency rise should be sought not in the bureaucratic machine modernization, but in the human being, in every person, in the use of his intellectual and volitional resources. However, to achieve this task, it has appeared necessary to make one important methodical step-to perform transition from the classical scientific rationality to the postnonclassical one (Vittikh 2012b), which doesn't separate the subject from the object (just as the classic science does it), but, on the contrary, takes into consideration the correlation of the knowledge derived from the object, with the individual features of the subject and the means thereof for activities (Stepin et al. 1996).

The fact is that even on physics lessons in the secondary school, the fundamentals of classical science, intended to acquire objective and true knowledge, usually being expressed in the laws of nature, were laid in our minds. We were told that this objectivity was achieved by separation of the subject (the researcher) jointly with the means of observation, from the object under research. The particularities of the scientist's personality and of the tools he is using "are carried out of the brackets", and it allows to assert that the law that has been found by this manner is valid always and everywhere (certainly, within the limits of some restrictions). And when, at the school, 
we used to solve problems in physics, or when, in the university, we were occupied with calculations of sustainability of the automatic control systems with application of the laws of mechanics, the conviction was gradually taking root in our minds that it was a classic scientific approach (with no exceptions!) which allowed the possibility to comprehend reality, therefore, such an approach should be used to solve arising practical problems.

However, when we came into collision with the real life problems, then, very often, we were disappointed. It turned out that natural science with its impressive and recognized scientific results when investigating the Nature, became powerless when we tried to solve the multitude of, and I even think, the majority of social, economical and humanitarian problems the mankind is deeply concerned about, because, instead of a clear material object (for example, technical facilities under automated control, without man participation) it was necessary to consider the community of people, existing in a one or another problem situation and seeking to find a way out, i.e. to control this situation. In fact, a human existence is always an existence in some situations (Zotov 2010).

Would it be rightfully, when following the classical rationality, "to carry" the people out of situation and to transform them into a certain "unified" subject who studies the object-situation-"from aside"? No, it wouldn't, of course, since the decisions, made and realized by the people being "inside" (and not "outside") of the situation, shall determine the development of such situation."And when everything in natural phenomena looks like "inevitable", which is caused by indisputable character of the natural laws, then "the freedom of choice" is always written on the artificial phenomena" (Simon 1972). But this is the human being who makes the choice: Herbert Simon has used the term "artificial" in the sense of "made by human being", to counterbalance "the natural".

In spite of the presence of such principal differences, quite often, when investigating any artificial systems, being created and in function with participation of the man (social, economical, socio-technical ones etc), the methods and means of natural sciences are applied. This is justified as long as particular models, fragmentary and reduced from "the whole", created on the basis of disciplinarily organized natural sciences; allow getting acceptable results for the practice. However, the man, the human being is not taken into account, although, quite often, there are talks about the need to consider the "human factor"- - a kind of a "correction factor" to the results of the "quasi-natural" processes modeling, taking place (with no man participation) in the object under investigation.

In this aspect, the behaviorists go a little bit further: the man is in the field of their vision, but is considered as a behavior system, which can be understood and described in the terms of stimulus and reaction. Such an approach is used, for example, at developing of pilots' behavior models by operating aircrafts, when there is, practically, no time for reflection. Nevertheless, in all cases when the principles of classical scientific rationality are applied, the human consciousness is not taken into consideration, and that is, as a matter of fact, a basic precondition of laying any bureaucratic organization which prescribes to the man who is reduced to the level of an automatic machine, to fulfill any rigid instructions, to follow any established procedures of actions in decision-making processes (we will consider the term " decision-making processes", following Johnson et al. (1967), as a synonym of "management processes"). 
The above-mentioned bureaucratic principles are the basis to construct Management, the decline of which was prognosticated by Cloke and Goldsmith (2004), since, in their opinion, the time of bureaucrats and functionaries has passed. They draw attention to the fact that the word manager is of the same root in English as the word manacle (handcuffs, chains, shackles) which evokes associations with the era of slavery and the slave trade, when managers acted as slave-drivers. In the era of serfdom, they became feudal managers controlling the serfs, making them, with the force of coercion, to work on the land of the proprietor, keeping the serfs obedient, collecting rents and taxes. With the coming of the industrial society, managers used to apply various forms of administrative compulsion and control, acting no longer alone, but within the framework of complex management structures that they started to build.

A whole class of managers was formed, i.e. the people, called up to manage the activity of other people, to impose their will on this people. The management, being supported by the bureaucracy, begun to transform "the function to manage the social systems into a direct or hidden power of individuals or of social groups as self-sufficient and reserved on themselves social forces (subjects) in public interactions" (The World Encyclopedia 2001). Managers in organizations become to be a privileged caste of employees, separated from their "ordinary" members and having as a main goal of their activity to keep their status (as minimum) and to grow in career. That is why the decisions are often made for the sake of personal benefits, but not for the organization's benefits, and the national objectives are transformed into any formal clerical targets. As a rule, the managers form a hierarchy, resulting in the appearance of a problem of responsibility distribution among them, which bears a "unilateral" character, since the top managers who possess more power may always dump the blame on the subordinated managers of lower levels. As a result, the true causes of erroneous decisions having brought to any undesirable and, often, to any sad consequences, remain hidden and can manifest themselves some day in the future.

These problems of management as well as many others, examined in Cloke and Goldsmith (2004), "reinforced" by a trite opinion that a person having been qualified as manager is capable to manage in any field of activity, generate (instead of the order conceived by the "ideal bureaucracy) an organizational chaos: endless coordination and talks, protracted retardations in decision-making, increasing flow of documents and lack of time to process them etc. Little by little, a belief that it all should be settled fades away. Furthermore, if to examine the problem by a larger manner, at the global level, it is to state that "at the end of the 20th century, the science lost its optimistic belief in potentiality of the social management to put in good order the world of human relationship, laid at the Age of the Enlightenment. Two World Wars which claimed millions of lives, bloody dictatorships of all kinds-from Nazism to Bolshevism, nuclear tests, accidents at nuclear power stations - this is the list of managerial catastrophes in the 20th century, which is far to be complete" (New Philosophical Encyclopedia 2010).

All that says that the management, in spite of constantly carried out programs of training and re-training of managerial staff at all the levels, is in the situation of a deep crisis. A forcible principle of the management organization is laid on the basis of this crisis, when one person (the subject) uses the other person as the means to reach his goals. Such a notion about management was being formed over the centuries and is 
firmly rooted in the minds of both managers-theoreticians and managers-practitioners, who are convinced that for achieving the goals in view (never mind if we want it or not), they have to force, in any case, the man to do what he doesn't wish to do. But such $a$ "slave" labor is not only contrary to the ideas of humanism that the human community put forward, it is simply ineffective. Therefore, there is an active search in the contemporary science for any new, alternative approaches to the management, designed to bring the society out of the crisis (New Philosophical Encyclopedia 2010).

The proposed theory of intersubjective management uses as a key notion the idea of the actor, who, in contrast to the manager, is the participant of non-violent methods of management, based not on coercion, but on mutual understanding and consensus with the other actors.

\section{Basic Concepts and Structure of the Theory of Intersubjective Management}

\subsection{Actor}

The Cartesian Ontology, as the doctrine on the Being, depicts a rational and mechanistic image of the world, subordinated to rigid laws where there is no space for the man and for the consciousness, i.e. the being is characterized by irrespectivity to the human activity, to their knowledge and thinking (Philosophy 2003). Correspondingly, the classical science and, particularly, the natural science, proceeds from the fact that the world can be described, without telling anything about the man which part is to be a detached observer, able to describe objectively (preferably on mathematical language) the events passing around him, without exerting any effect on their course (Dictionary of Philosophical Terms 2004). And this objective knowledge is deemed to be a true one. Such is the logic of classical scientific cognition.

Scientism, rendering absolute the social role of the science, created an ideological foundation for the use of classical scientific rationality at investigations of social, economical, socio-technical and other artificial systems, which resulted in the need to be distanced, to dissociate the man from them. There were some scientists who worked (and still go on working) in this direction. But such artificial systems cannot be created and function in essence without participation of the people who, by their decisions and actions, direct the development. Therefore, the man cannot be excluded from the theory of management, and this, as a matter of fact, leads us to the change of the scientific paradigm - transition from classical to postnonclassical scientific rationality (Stepin et al. 1996; Vittikh 2012b). At the same time, a change of concepts on ontology is taking place.

If the Cartesian ontological constructions consider the objective material world outside and without the man, the fundamental ontology of M. Heidegger understands the Being, first of all, as the Being of Man, i.e. the doctrine on the Being appears as the Ontology of Subjectivity (Zotov 2010): the Man is placed in the centre of the subject world which he constructs in his mind. By following Heidegger (2003), we move from the "objective" world to the "subjective" world, and an individual, a human person occupies the place of the unified subject of the classical scientific rationality. 
Based on the above-stated, we see appearing a concept which is fundamental for the theory that we are working out - the concept of actor, i.e. the man, who, in contrast to the subject of gnosiology, not only cognizes the world, but creates it. Each actor has his own point of view on the world and on the processes therein, and, in this sense, the actors are heterogeneous. When occurs that they are bound by a common problem situation, the actors realize it differently, although they recognize simultaneously the necessity of any coordinated actions to control the situation and they are liable for the consequences of the decisions they make. Therefore, they make any communicative actions, i.e the actions that are consciously oriented to its semantic perception. Communicative action, pursuant to Habermas, is such an interaction of individuals, which is regulated accordingly to any binding norms and oriented towards attainment of mutual understanding by acting individuals, of their consensus (New Philosophical Encyclopedia 2010; Social Philosophy: Dictionary 2006). So, the basic function of the communication is the attainment of social community, individuality of every element therein being retained. Habermas, in his theory of communicative action, considers communication as the basic social process (The World Encyclopedia 2001), i.e. social reality is constructed by means of images and notions, expressed in communication. In other words, the actors are supposed to be communicatively rational. The communicative rationality, which is, in the philosophy of Habermas, the rationality of solidarity and collaboration, is opposed to any forcible rationality of management, directed to the use in its interests of other people. With that all, the communicative rationality is based on the intersubjective nature of the human mind.

Intersubjectivity is a structure of individual consciousness responding to the fact of existence of other individuals. So far as "I" can only partially compose the world, it receives from "the others" what it misses in its own experience (Modern Philosophical Dictionary 1998). The world that we discover in the consciousness is an intersubjective world (Philosophy 2004). Intersubjectivity represents a specific community among the cognizing subjects, any conditions of interactivity and of transfer of knowledge owned by one for another (The World Encyclopedia 2001). Subjective knowledge, significant and "sure" (relatively true) for one actor, may be also valuable for the other actors, being together with him in the same common problem situation, which compels them to interact and to participate in a joint decision-making. Then, following the conventional concept of truth by H. Poincaré, who interpreted the truth as the result of a convention, we may achieve an agreement to recognize certain subjective knowledge to be true for a restricted circle of actors in communication. Such knowledge may be called intersubjective (Vittikh 2011).

The above said relates also to value orientations which key to understand should be sought not in any subject-object relations of the people, but in intersubjective relations of the same (The World Encyclopedia 2001). The actor, each of them having his own world outlook, must compromise when choosing the system of values, since, otherwise, it would be impossible to attain mutual understanding and consensus during the decision-making. Often, this problem is artificially simplified, when, without any discussion, the position of one of the actors is accepted, who has expressed it by any target program he had prepared and which reflects only his point of view. A thesis is postulated: "We shouldn't waste time in talking, we have to do business". So, the program is adopted and comes under realization, but soon, it becomes clear that the 
results thereof don't lead to any settlement of the problem situation; moreover, there are new problems appearing which demand much bigger expenses in comparison to those which would have been made at in-good-time-considered positions of the other actors.

It appears to be important, herewith, that the actors use discourse - a form of communication during which the statements of the "other" are thoroughly checked, understood, refined, criticized and finally accepted or rejected. In the discourse, the main role is played by argument, and coercion to consent is forbidden (Habermas 2006; Solovieva 2009). Habermas considers the discourse to be an original criterion to determine if the achieved consent is true or false (Modern Philosophical Dictionary 1998).

Thus, in contrast to the manager for whom the principal tool to manage is a "vertical" coercion and impact, the actor uses a "horizontal" interaction to achieve consent, consensus, being supported by the solidarity of the actors. Solidarity (in the philosophy of Rorty) is the turn of mind (opposed to the traditional objectivity) to unite various points of view not on the platform of identity, but in the context of their differences. These differences, according to Rorty, provoke no world outlook conflicts, but create conditions for a free choice. No one among the positions united on the foundation of solidarity pretends to the status to be sole, and that distinguishes principally this approach from the classical rationality, based on the idea of possibility and accessibility of one sole right decision (Vittikh 2009a). Rorty denies the need in a semantic centre, supposing that the social hope is called to be supported not by "objectivity" but by "solidarity" (The World Encyclopedia 2001). Besides, the solidarity is deemed as a unity, an attraction of diversities, and not as uniformity, because the world gets renewed through the contacts of diversities; "in their unity, the diverse "ones" complement each other and grow up to the parts of the whole" (Modern Philosophical Dictionary 1998) In this case, the system (the whole) "is grown from the bottom to the top" on the basis of lowerarchy (Ackoff 2009), when the "lower" elements are the source of resources and power for the "higher", in the contrast to a hierarchical organization "from top to down", based on dictates of the supreme power.

The adherents of the management will not fail to note a potentially low discipline of the actors, since, in the basis of such discipline, there are "soft" and "liberal" intersubjectivity and solidarity, assuming availability of a high level of "consciousness" of the actors, which is extremely difficult to reach in the real life. "Discipline should be based on coercion and violation"- they would say. Indeed, it is not entirely true, and more specifically, not at all. The fact is that the discipline is a term fixing the obligatoriness of subordination by "everybody" (human community, social groups, individuals) to any established order (norms, rules etc), ensuring good organization, firm structure, co-ordination and expectancy of interactions inside of a social integrity (in its statics as well as in its dynamics and procedures), and this is ensured by any "external" (coercion) and "internal" (interiorization of norms etc) mechanisms to maintain discipline in the society (The World Encyclopedia 2001). It follows from this definition, that not only coercion, but also personal convictions, fully formed as a result of adoption of social, cultural and moral norms and values, may discipline the behavior of the man. That is why, the theory of intersubjective management supposes that the actors are "inwardly" motivated to communication and coordinated actions, but the only way to reach it shall be a duly organized education. And what's more, it is to be during the 
process of socialization of the individual in his young years, while the system of the individual's own views on the world is under formation. As a matter of fact, the question is to educate the actor' will-phenomenon of the self-regulation by the subject of both his behavior and activity, providing the consciousness orientation and efforts concentration towards the achievement thereof (The World Encyclopedia 2001).

Today, the basics of management training is conducted in the spirit of classical management with its ideology of violence and coercion, but our entry into the information society will be accompanied by dissemination of communicative rationality and, correspondingly, by non-violent intersubjective relations among the people in the processes of management (decision-making).

\subsection{Situation}

The human being is the being in situations (Zotov 2010). "The whole man's initiative is not only situationally determined, but situationally framed ... The man has to act in a situation, but the situation doesn't specify to him how to act exactly, and therein lies his freedom... The situation is coercion to the decision; the freedom is in the decision it-self" (Hartmann 1997).

At first sight, the situation is presented as an objective reality not depending on the man's subjective point of view, but if to take in consideration the human consciousness, it would be an error "to object" the situation, to consider it as something that exists by it-self. "The situation is an ambiguous phenomenon; one cannot recognize therein the degree of freedom's part and the degree of rigid position of things" (Zotov 2010). For example, an abundant snowfall is an objective natural phenomenon. But we realize it differently: this snowfall gets on the car driver's nerves: it might provoke traffic jams; the employees of housing and communal services are worry about snow removal equipment's capacity to cope with it; children anticipate pleasure to play in snowballs, etc.

It is important that the man can understand the situation only "from the inside", but not from the positions of an external observer. That is why it cannot be interpreted as either "objective" or "subjective" (Zotov 2010). In our example, a snowfall provokes no emotions at a car driver, if he is not going to drive out; at an employee of housing and communal services, if he is on leave; at a child, if he is ill and the parents don't allow him to go outdoors. In the above specified conditions (no need of car, a leave, an illness), all the mentioned individuals become external observers.

Moreover, the man finds him-self to be not alone in the situation; Jean-Paul Sartre wrote about it: "I exist in the midst of other existents and I can accept neither this others existents only in the quality of objects, nor myself as existing only encircled by the others. The situation is my position in the world, defined by relationships of utilization and resistance of those realities that surround me... The structure of situation takes shape from "my place", "my body", "my past", "my position in relation to others" and "my fundamental relation to the other" (Zotov 2010).

Thereby, every autonomous heterogeneous actor will "be preoccupied" in his own way (according to M. Heidegger) about the situation, when this actor is placed in the centre of the "subjective world" which includes all that his preoccupation concerns. The description of the subjective world is the subjective (personal) ontology, comprehended as "the description and organization of what there is, of the multitude of 
existing things, and which determines how these things are interconnected" (Merrill 2003).

However, the situation may be comprehended by the actors as the matter of their common care connected with the need of a joint decision-making for the purpose to settle it. Then, elaboration of an ontological model of situation is required, i.e. a coordinated description of the situation in the form of concepts and relations through a multilateral dialog of heterogeneous actors (Vittikh 2009b).

It is to note that the necessity to make decision is comprehended by the actors not in each situation. It is required for this purpose that they get unsatisfied by the state of matters or, speaking generally, it is necessary that the degree of situation indeterminacy should exceed a certain admissible threshold. In this context, we may speak about a problem situation, when an unsatisfied state of matters is already comprehended, but it is not yet clear what should be done to change it (Novikov and Novikov 2007).

There is multitude of sources of situation indeterminacy: natural, technological, etc, but the main source is heterogeneity of actors, differences of their world outlook positions. That is why, communicative actions, aimed to mutual persuasions, search of compromises and convergence of points of view, play a key role in the processes of attainment of actors' mutual understanding and consensus, which, finally, provide situation indeterminacy decreasing down to any acceptable level.

In concluding this section, it is appropriate to make a comment referred to the separation of the notion of "strategic management" and "situational (non-strategic) management" which seems to be rather arbitrary. In the Vikhansky and Naumov (1999), strategic management supposes "a look from the future towards the present", and nonstrategic management supposes elaboration and implementation of a plan of transition from the present (and, correspondingly, from the past) to the future, provided that the "environment will not be changed actually". However, the man, in his "present", possesses not only "the past", but, similarly, the man realizes in the "present" (in the current situation) his own "future" (Zotov 2010). The fundamental ontology of M. Heidegger attaches a primordial importance to the notion of "now" which includes both the past and the future. "The presence, he writes in his Heidegger (2003), is its past by the manner of its being, which ... every time comes true from its future". Such ability of the man to apply the desirable future for decision-making in the present is evidence of his power to manage "strategically". And, at the same time, he can carry out a "non-strategic" management of "linear" development from the past through the present towards the future. In other words, there is no need to distinguish strategic and situational (current, operative) management, as far as, figuratively speaking, these are two sides of the same coin.

\subsection{Communication}

As soon as the heterogeneous actors begin to comprehend (individually at first) the problem situation, they proceed to the communicative actions in order to understand the situation in concord, i.e. to attain mutual understanding, then to find, by concerted efforts, a solution which would be convenient for everyone, to settle it. Thus, the communication is not identified herein with narrower notions of connection and 
information transfer, but it shall serve as the means of provision for the actors' mutual understanding.

Usually, the classical management which is built on the principles of bureaucracy doesn't set such a task. The manager communicates with his subordinates, basically, for the purpose to get from them information which he needs to make a decision, but he has no necessity to achieve any mutual understanding. A similar picture may be seen in any collective management when each member of the collective, being responsible for a determined "his own" sphere of activity, is far to seek to delve deeply into the substance of the concerns of his colleagues. If anybody among them has prepared a draft decision, it will be coordinated more often formally, if only it wouldn't contradict any interests of others. With that all, the main argument they adduce is the "lack of time" for an intersubjective activity, any extraordinary circumstances being put forward.

We can agree that in any emergency situations there is no time for reflection, discussion and negotiation, as a rule. But it doesn't mean that even in "ordinary" problem situations one must obey the will of some single authoritarian manager. "Firefighters" decision-making methods should be used only in appropriate situations. In any other events, the actors must understand each other and act in concord. The question is how to attain this mutual understanding.

It is to note first of all, that the question is about the negotiations of the actors, intended to render their positions closer, in results of which they achieve a general consent on the disputed issue, i.e. consensus (no formal voting is supposed to be conducted). Habermas believes consensus is exactly the main goal of communications, aimed at understanding, and from the standpoint of consensus' reachability, he emphasizes a particular form of communication: a discourse, when consent is reached in result of arguments and not of coercion. Habermas gives the name of "ideal speech situation" (Modern Philosophical Dictionary 1998) to the conditions that can allow such a rational consent.

Habermas develops the concept of discourse as a special form of speech communication based on reflexive dialogue, accentuating all the aspects, significant for the participants, both of the subjects under discussion and of the dialogue's situation (The World Encyclopedia 2001). He proposes, in his discourse ethics, to take into consideration not only the significance of any firm moral norms, but also the degree of possible solidarity of discourse participants (New Philosophical Encyclopedia 2010). So, the discourse is understood as an ideal form of communication implemented out of touch with traditions, authority etc, and aimed at critical discussion and substantiation of opinions and actions of the communication participants (Modern Philosophical Dictionary 1998). The discourse thinking, displaying in succession of notions and judgments, is set in opposition with an intuitive, comprehending the whole, independently and without any successive display (New Philosophical Encyclopedia 2010).

With the assistance of discourse, a free and void of any restrictions communication of actors, having for an object to reach their mutual understanding, becomes rational. It is to add that the society is deemed by Habermas not as a social construction, but as a communicative mechanism which determines not only dynamics, but also the essence of social processes (Loskutnikova 2011). Habermas takes as a principle of a social life's theoretical interpretation not any material productive forces, providing an onward transformation of the Nature by human being, but a "productive force of com- 
munication", weaving the social substance and providing its onward rationalization. It is exactly the communicative way of actions, where the co-ordination of participants' plans of actions is implemented through a mechanism of mutual understanding in the environment of the natural language, that provides reproduction of the society as a "life world" (Furs 2001). In other words, a communicative view on the world will take on a more and more increasing significance.

\subsection{Self-Organization}

Autonomous heterogeneous actors operate, not waiting for orders from any central managing body, they organize themselves in communicating with each other and elaborating concerted decisions how to control the situation with taking into account the common interests and not forgetting their proper ones. The self-organization is understood as a spontaneous unplanned emergence of order (of certain global structures) derived from fortuitous (chaotic) local interactions without any outer organizing impacts (Kueppers 1999). The social systems, in this sense, are not exclusions, since manifestations of self-organization are discovered as far back as in the primary social form of the primitive system i.e. a community where the general meeting of the community's members served as a social institute ensuring the execution, without mediators, of the self-organization functions based on the principle of "each for all and all for each" (New Philosophical Encyclopedia 2010).

The relationships of self-organization in the community of that time had the character of a "primitive democracy", and the governing structures were directly "interlaced" into the great bulk of the community's members (Modern Philosophical Dictionary 1998). Emerging problem situations, affecting the interests of the community's members and possessing an indeterminacy, were being regulated, by way of local interactions, at the summit gatherings of the community, where, in the persons of the community's members themselves, a merger of "legislative" and "executive" power were taking place (New Philosophical Encyclopedia 2010). In other words, ability for a social self-organization was the community's foundation, providing an opportunity to carry out managing processes (decision-making processes) (Johnson et al. 1967).

Being in a "natural condition", wherein any moral and legal restrictions were practically absent, an individual possessed, nevertheless, all the rights of self-protection, and he used to act following the "natural law" that reflected an elementary idea of justice. Having passed to the "public status", the people transferred the function of the "natural law" interpretation to the legislative power's bodies, and the function of selfprotection-to the executive power's bodies (Dictionary of Philosophical Terms 2004). Appearance of a mediator in the person of State as machinery to govern the society, provided with the power and supported by the force of law or by the bodies of coercion, changed the communal model of self-organization. Now, the self-organization was being carried out at the level of local interactions of the people only when the indeterminacy of situation could be regulated by means of direct negotiations without referring to involve such global structures as State authorities and normative legal acts elaborated thereby. Whenever an indeterminacy of any situation in the human community (e.g. social tensions) exceeded a certain critical value, then an intervention of the State with its powers was needed to regulate social relations. Changes of these 
relations, in its turn, gave "urges" to the authorities from the society for elaboration of any new forms of behavior and interactions of people at a local level. So, such $a$ circular causal dependence, coupled with the indeterminacy of situations, forms the basis of social self-organization in the contemporary ("non-communal") sense of the word (Kueppers 1999; Vittikh 2002).

However, the tendency to extend the sphere of regulation by State of the people's life and activity (even in those events when there were no needs at all to do so) developed the system of compulsory cooperation, putting down, little by little, the public self-organization. H. Spencer named "militant" this type of society. People who form a militant society, "must possess a blind faith in authority and readiness to be guided by the others, and, therefore, comparatively small initiative. The habit to see everywhere an official intervention develops the certitude that this official intervention must be everywhere; and the mode of life, when everything is determined by a personal discretion and there are no examples of impersonal course of events, renders them unable to understand any social processes as a result of self-regulatory orders" (Spencer 1997). In such a society, the centralized governance, drawing the decision-making up to the top authorities, pushes the social self-organization to the background, reducing the people into a "cog" in the State-owned bureaucratic machine, into ordinary executors of the will of other people.

At the same time (as we have mentioned in the Introduction), the reserves of quality of life rise, of economy efficiency and of State governing should be sought in the people themselves, in each human being, in the use of his personal intellectual and volitional resources. But a rigid administrative hierarchy and centralization, binding the people's initiative, are unacceptable, so far as, to resolve this problem, it is necessary to maintain the development of self-organization as a fundamental property of any complex social system. Pitirim Sorokin, classical sociologist, accentuated his attention thereon. He wrote that "one of the most principal factors determining the functioning and development of any system lies inside of it-self. In this sense, any inside integrated system is an autonomous self-regulatory, self-governing or, if you please, a "balanced" unity" (Sorokin 2006). It is exactly the self-organization that plays a key system-generating role at emergence of order from chaos (Prigozhin and Stengers 1986), representing disordered primeval origins, primitive matter, from which the world was formed (New Philosophical Encyclopedia 2010). We may consider, at this basis, the self-organization as the main way of genesis of the most different objects (including social ones) and join us to the idea about primacy of the self-organization phenomenon (Chaykovsky 1993).

\subsection{Intersubjective System}

In their aspiration to understand the sense of the problem situation and to settle it by decreasing the situation's indeterminacy down to an acceptable level, the autonomous actors organize themselves into a system which we shall call an intersubjective system (Vittikh et al. 2012a). Each actor, together with intellectual, material and working resources in his possession, forms a basic element of an intersubjective system,

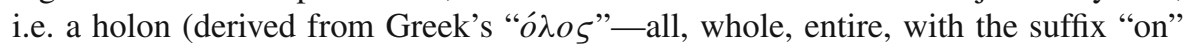


indicating a part, a particle) (Koestler 1989). The notion of "holon" means a whole, being a part of another whole, including in it-self any components under the actor's control intended for processing, transporting and storing physical objects (substance, energy) and information. Being independent and autonomous, the holon, disposing of developed communication means, is able to interact with other holons, forming new (composite) holons. In other words, an intersubjective holonic system is constructed on the "part-whole" principle, in contrast to the systems being organized on the basis of "cause-effect" relationship among the elements (Vittikh 2010).

Holons can not only unite (integrate themselves) into composite holons, but, on the contrary, break up (disintegrate). Processes of integration and disintegration of the holons determine evolution of the intersubject system, which must be considered as a developing system (Ackoff 2009), always remaining open and uncompleted. The fact is that in processes of realization and regulation of the problem situation, the composition of participants (holons) may not only be changed, but also their agreements, connected with their priorities, guiding lines and requesting solutions tasks, may be corrected. Thus, this is communicative rationality that must predominate in the consciousness of the actors who direct, by their decisions and actions, the development of an intersubjective system, and not the rationality of target which supposes a rigid orientation to a "set from on high" target and plans being subject to a rigorous execution. To illustrate the above-said, let us apply to some examples.

The Volga Automobile Factory (VAZ, abbreviation of Volzhsky Avtomobilny Zavod) in Togliatti was created to manufacture motor-cars under the prices which would appropriate the purchasing capacity of the population, i.e. with the purpose to meet public demand in this kind of industrial goods. In order to conduct economic and technical feasibility as well as production planning studies, an Italian factory which produced the FIAT motor-cars was taken as prototype. As a result, a national automobile factory was designed being a rather close copy of the Italian original; it was clear, prior to the construction of VAZ, what, how and with the use of what resources the production would be organized. Nobody doubted that only a program and target-oriented method of planning and management, requiring a strict execution of established regulations and procedures on each production site would ensure achievement of the given task. The factory was built, the production of motor-cars was mastered, and the products began to flow to consumers. So, if all the surrounding conditions had stayed stable, or were changed by the manner that had been foreseen by the plans, then no problems would have been arisen.

However, since those times the world has been becoming more and more open and dynamic; consumers requirements have been changing, the demand for motor-cars, in virtue of its stochastic nature, has been badly amenable to predictions; the market has begun to receive the manufactured abroad motor-cars, which are in competition with VAZ models, etc. The VAZ production lines needed in modernization, in technical reequipment, serious problems with personnel arose, etc. But the centralized bureaucratic system, laid already in the basis of the enterprise management at the design stage, turned to be unable to master with this always growing "snowball" of problems.

In the middle of the 90-th, a tentative was undertaken to reform the VAZ management system towards its decentralization: VAZ structural subdivisions were becoming autonomous "business unities", acquiring a relative independence and freedom of 
choice in regard of kinds of activity with the purpose to achieve a higher profitability level. In the issue, the economy of the enterprise would have to be much more efficacious. Nevertheless, for the different reasons, this reform was not fated to come true.

Let us examine, as an alternative example, the organization, and more precisely, the self-organization of Silicon Valley in California (USA), which was "engendered" and "cultivated" as an intersubjective (and non bureaucratic) system. It is known from the history of Silicon Valley origins, that in 1937, two graduates of the Stanford University (two actors) - Bill Hewlett and Dave Packard decided to unify the resources in their possession and to found, in the garage in Palo Alto, an office of their company and a small workshop (basic holon) to develop electronic devices. This action gave rise to the development of one of the biggest world companies: the Hewlett-Packard (HP). The Company's founders didn't aim to install a production line and to sell any specific devices or equipment, because, first of all, they wanted to create a company of great vitality, the profits of which would derive from the use of achievements of science and new technologies. Therefore, the key role in the Company's organization and development was played by knowledge (and not by a status position) of the collaborators, by their solidarity (and not by an administrative coercion) and by readiness to harmonize their personal interests with the corporative ones.

The idea to found their proper company was given to Mr. Hewlett and Mr. Packard by the professor of Stanford University Frederick Terman, who, being worried about the mass departure of the University's graduates ("brain drain"), began to support actively the other Stanford students (potential actors) in their aspiration to found companies not far from the University. As the result, without any "steering" administrative body participation, a network of research and industrial firms started to get formed around the Stanford University, which the journalist Don Hoefler called in 1971 the Silicon Valley. By the way, Frederick Terman is widely credited with being "the father of Silicon Valley".

The firms (holons) situated on the territory of Silicon Valley, are interacting in a natural manner with each other, getting "integrated" and "disintegrated", and, as a result of this, a synergetic effect is being created, i.e. birth of new scientific and technological knowledge which is further converted into profits and corporative development.

Thus, Silicon Valley may be considered as an intersubjective system, being developed on the basis of lowrarchy- "from bottom upwards". Anyhow, it doesn't mean that there is no place for hierarchy in such a system. Autonomous actors, possessing sufficient freedom, may agree among them to establish hierarchical relationships when the interests of the common cause require it. Nevertheless, the principles of "ideal democracy" formulated by Ackoff (2009) in his work should be followed herein:

- everyone among those who may be affected by a decision that is being made must be able to participate directly or indirectly in this decision-making;

- everyone who possesses authority over the others must be subject to collective authority of the others over him;

- an individual or a group may do whatever they like provided that it doesn't affect the interests of other subjects. If this may affect the others, the action must get approved by these latter or by their proxies. 
In the same article, Ackoff gives a short description of a "purely" lowrarchical structure of a well known Visa Corporation, which may be considered as an intersubjective system. "Un example of a radically decentralized organization, in which the initial authority rises from below, is given by Visa where its users are its owners. Dee Hock, the founder of Visa Corporation, called this company "an overturned holding". By contrast with a holding, i.e. one company possessing many other companies, Visa is the company owned by its member banks and other institutes-issuers of Visa cards. They are simultaneously its owners and its users. In many cases, they are also its suppliers. Organizational structure of the Visa Corporation was deliberately designed as a "federative" system, and it comprises series of regional, national and international organizations, each of them having its own members and board of directors. Each organizational level receives its authority not from upper but from lower levels. Decisions are made by votes of boards at various levels, with a two or three months' cycle of a matter passing through all the levels. For example, the Visa Corporation members voted on the matter of service costs for themselves to all the Visa transactions and to some other payments for additional services. However, the members of the organization are free to decide which Visa product to use, or to leave entirely the Visa system, or to offer a competing product" (Ackoff 2009).

\subsection{Structure of the Theory of Intersubjective Management}

There are following distinctions between the notion of "theory", adopted in classical natural science, and interpretation of this term which is used with reference to intersubjective management:

1. If the natural scientific theory is aimed to detect and to uselatent forces of Nature, then the theory of intersubjective management is aimed to intellectual and volitional resources of people in the processes of decision-making.

2. Classical scientific rationality, focusing attention on the object, excludes, at theoretical description, everything that relates to the subject and to the means of its activity; thus, the man with the means of observation finds him-self out of the object and outside the theory. Postnonclassical scientific rationality, being a methodological foundation for the theory of intersubjective management, proceeds from the following: a subject, together with means of observation and of activity, performs a cognitive-activity-function, being inside of the object (of the situation), and, correspondingly, a man and means of activity are component parts of the theory.

3. Unlike classical scientific theory dealing with a universal idealized object, the theory of intersubjective management is an ad hoc theory related to a unique idealized object i.e. a situation which is realized and controlled (regulated) by the inside being people i.e.actors.

4. It is admitted that natural scientific knowledge is objectively-true, whereas, in the theory of intersubjective management, the knowledge of actors is subjective or intersubjective. Nevertheless, the fact is not refuted that each actor has a certain reserve of generally admitted objective scientific knowledge he acquired in school, university or throughout his practical life activity. 
5. Classical scientific theory is created "for all the time" and is applied (as required) by the theory users for the purpose to solve the emerging before them problems, but the ad hoc theory of intersubjective management is developed and applied by the actors themselves at the pace of situation development, i.e. in real time. Figuratively speaking, actors are "both authors and performers of their own drama which is cognized by them, after all" (Kokhanovsky et al. 2004).

Thus, the structure of theory of intersubjective management comprises:

- heterogeneous actors, endowed with intersubjectuive consciousness and holding on communicative rationality;

- intersubjective system - a holonic system with developed means of communication, providing possibility to attain mutual understanding of actors in the processes of decision-making to regulate the situation;

- personal knowledge of each actor, expressing his material world positioned "in the field of view" of the actor prior to emergence of the problem situation (i.e. this is the pre-understanding of the situation) (Vittikh 2005);

- intersubjective knowledge — shared and admitted by all actors, realizing themselves to be in a specific situation, results of their agreement and consent on the basis of what principles, rules and norms the decisions to control the situation will be made (i.e. these are achieved agreements about "the rules of the game" in the processes of decision-making).

These agreements are attained by the actors within the framework of the following types of intersubjectivity (Huebner 1996).

Semantic intersubjectivity assumes explicitness and common consent with regard to notions and judgments built of them, i.e. they are understood equally by everybody and therefore may be applied in the same way.

Empirical intersubjectivity implies that statements that are based on empirical facts are designated as rationally substantiated. In this case, it is necessary to have possibility to clearly understand these facts, they must without fail be acceptable and recognized by somebody, i.e. well-founded nature of judgments by facts and observation is recognized to be necessary.

Logical intersubjectivity considers as being rationally substantiated such statements which are a result of logical deduction. This also assumes intelligibility, explicitness and overall acceptability.

Operational intersubjectivity proceeds from reproducibility of patterns for actions and reasoning. It is assumed that a certain sequence of actions is always based on this pattern in an explicit, generally and obligatory accepted manner. Single elements of such a technology and their sequence that compose this pattern are understood by everybody in a unique manner and, in principle, can be reproduced in the same form.

Normative intersubjectivity assumes general acceptability of norms and rules of behavior and appraisal. If a certain activity is guided it-self by norms, it is also considered as being rationally substantiated. Although, a norm is at the same time a guide to action and, in operational sense, doesn't differ often from this latter, nonetheless, the word "norm" is usually associated with specific value preferences.

In conclusion of this section, it should be noted that the above-expounded nonconventional understanding of the term "theory" is in consonance with the ancient 
(platonic) notion of "theory", which is contained in the monograph of Losev (1969). In his opinion, "the Plato's term of "theory" represents such state of consciousness which has as its object an organized and shaped reality and which designs analyticallysynthetically this reality on the basis of direct vision and contemplation. In the other words, we discover in this term a mutual merger of a directly given and of a consciously designed objectivity, so typical for Plato and for the whole Antiquity". Thus, the Plato's term of "theory" has nothing to do with the modern European meaning of the word" (Losev 1969).

\section{On Elaboration and Appliance of the Theory of Intersubjective Management}

\subsection{Process of Decision-Making with Appliance of the Theory of Intersubjective Management}

The theory of intersubjective management, as it was noted in the previous section, is intended to achieve a mutual understanding of heterogeneous actors in the process of decision-making on how to regulate a problem situation; this theory, being elaborated by the actors themselves, plays the role of a peculiar "integration platform", assisting to converge their positions.

The traditional theory of decision-making (see, e.g. Zub 2010) poses no question about any mutual understanding, and this is rather strange, since it is difficult to imagine a more or less satisfactory decision which would be made under such conditions when interested persons didn't understand each other. More precisely, this question is raised sometimes, but in an absolutely different formulation which assumes that the person who makes the decision is a leader (manager), and all the others are detached observers. Therefore, the text-book (Zub 2010) notes that "the decisions made by the leader are under an intent look both of subordinates and of multiple observers... The leader performs the role of a thinker who looks to the future. He must possess vision of prospects of problem situation's development and explain to the subordinates the interdependence of events".

Thus, we see here the manifestation of ideology of management oriented towards "the cult of bosses": leader is the thinker, strategist, master etc, whereas the people around him need to be protected and watched over by the leader, but they-self may not show any initiative. This idea gets, rather often, a curious continuation: if someone is a leader, then it means that he is supposed to be a creative, well-educated, highly professional man, even with an impeccable moral reputation. But, unfortunately, this is not always the case.

The theory of intersubjective management has absolutely different and, in a certain sense, opposed prerequisites. In place of managers, i.e. professional chiefs, we see appearing of united actors, realizing the problem situation and, at the basis of partnership relations, striving to regulate it, observing the attained agreements and resorting to no forcible methods (including administrative coercion). In the quality of actors may appear citizens, representatives of authorities, business and social organizations who may have, as a rule, quite various and contradictory interests.

The representatives of business will strive to get profits even when they participate in any social projects, an official will try to keep his "position in the authority", 
providing (accordingly to his official functions) the population with governmental services. Against such a multiple background of aspirations, a match of interests will be most probably a rare exclusion. Thus, diversity becomes a source of conflicts in the processes of decision-making by heterogeneous actors. The question is how to treat the conflicts.

One position is to eradicate conflicts by all possible (political or spiritual) means. "Overcoming of a social conflict, from this point of view, must lead to harmonization of social relationships, to some ideal condition, happy harmony, to a life without struggle. The implementation of ideal of a conflict-free state is transferred, as a rule, to the long-term future and to the afterlife ("City of God"). The more realistic theories of social relationships considers a conflict as a constant and irremovable component of the public life which is, in either event, included into the structure of cooperation (through competition in the common cause, contest and manifestation of initiative)" (New Philosophical Encyclopedia 2010).

Thus, another point of view is to regulate conflicts, and not to eradicate them. It is based on the theory of a free society which represents a gathering of a community (and, accordingly, of authorities), united by laws which recognize the right of individuals to be united with those and in such a manner as they like. A model of a free society provides an existence of a multitude of associations, but no one among them is "privileged" and no one has any special moral importance... The theory of free society is a description of conditions under which various modes of lifeco-exist, but not a description of conditions under which they are drawn into a mutual conformity (Kukathas 2011). The concept of free society and conflicts regulation is laid into basis of construction of the theory of intersubjective management, which, in its turn, plays a key role in the process of decision-making to regulate a problem situation (Fig. 1). Let us examine the main stages of this process.

\subsection{Formation of Intersubjective System}

In proportion as they become aware of the problem situation, the heterogeneous actors start to communicate with each other, forming an intersubjective system, within the framework of which they will conduct negotiations about acceptable for everyone way to go out of the arisen situation. Intersubjective system is an open system, having a holonic structure, which, in the terms of the work (Kukathas 2011), represents "community" as an association of "partial associations". Here, we can trace back the similarity of the positions of Koestler (1989), being the first to suggest to use the notion of "holon" as a basic element of systems organized on the principle of "partwhole", and Kukathas, who, being based on a similar approach, gave the definition of "community", by answering an important question, what of common must have people for being considered as a community (Kukathas 2011).

The fact is that a community is not only an aggregate of individuals, not only that to which they just belong and of which they are members. The problem consists exactly in the fact that we call communities the most various kinds of human associations. For example, Kukathas examines in Kukathas (2011) the model of F. Tönnies, "who distinguished a community from an association by the principle that the members of community not only live close by, they have also a certain common origin. Associations 

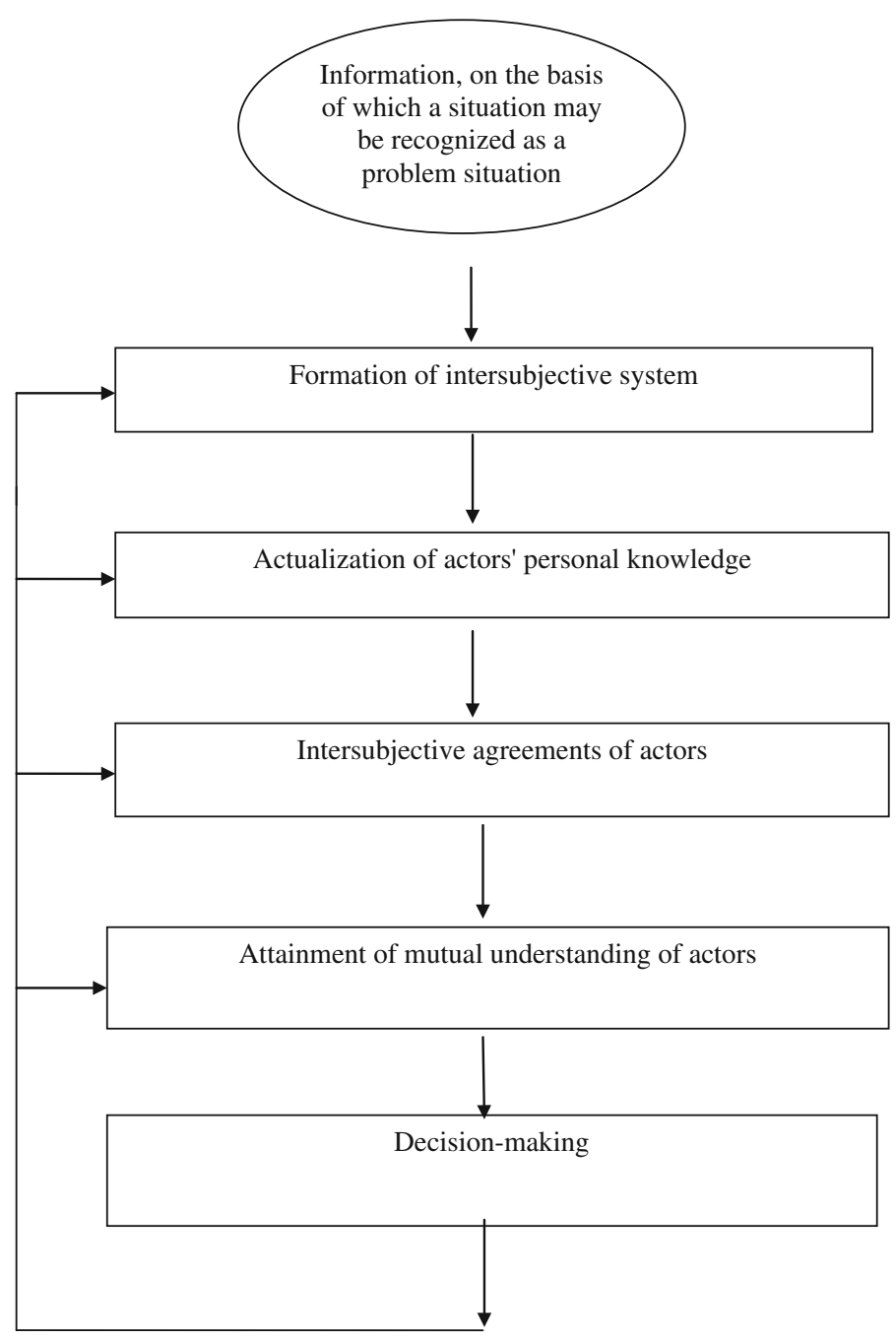

Fig. 1 Process of decision-making to regulate a problem situation

may be founded and constructed, but a true community is formed by a natural manner, on the grounds of kinship and family relations, as well as on the grounds of habitats, views and experience. In this sense, one can be a member of a community only if he was born in. And, as far as everything is focused to the question of birth, status and views, but not of an agreement and interests, living in one place is a necessary but not a sufficient condition for existence of a community".

The other community model of Maclver emphasizes importance of the unity of interests. However, as Kukathas notes, availability of common interests doesn't convert a group of people into a community. For example, people at a bus stop are interested in a timely arrival of the bus and a well-ordered getting inside, but they don't become a community because of that. And then, he gives his proper definition of community: 
"Community represents an aggregate of individuals with common understanding of what, in the framework of this aggregate, refers to the public sphere and what refers to the private one" (Kukathas 2011).

Based on this definition and assuming that the intersubjective system is a community, we come to the fact that the actors must agree with each other and recognize the achieved agreements with regard to common interests, but not forgetting about their own interests, i.e. they must have a certain mutual understanding of difference between a public (a group) sphere and a private (an individual) sphere.

A community appears where there is this mutual understanding; it also follows from the above-said that "many varieties of associations, the members of which are dispersed at a large expanse, are still communities" (Kukathas 2011). Awareness by each actor of his membership in the community plays a primordial "starting" role in the process of decision-making to regulate a problem situation.

The actors, together with resources they possess, form holons, and the common "preoccupation" that they have recognized, performs a system-forming function when the intersubjective system is self-organizing.

Important is also recognition and understanding of the fact that a man-actor can simultaneously realize him-self in several problem situations and, correspondingly, in several intersubjective systems. For example, resolving any problems in his office, the man can simultaneously be concerned by the state of health of his close relative in the family; therefore he has to share loyalty between these problems, his resources, making a choice: be concentrated on performance of his office tasks or to visit a chemist's shop, to buy some medicine and to bring it for the sick person. Therefore let us briefly examine the approach to solution of this problem of loyalty conflict, proposed by Kukathas in his Theory of Diversity and Freedom (Kukathas 2011).

The author of this theory proceeds from the fact that each man belongs to a multitude of communities and shares loyalty among them. These loyalties clash with each other (in our example, the loyalty related to the office tasks clashes with the loyalty related to the family).

Fundamental principle of a free society is the principle of freedom of associations, and the first conclusion from it isthe principle offreedom to leave association. The second conclusion is the principle of mutual tolerance of associations (Kukathas 2011). In contrast to the Plato's "State/Ship" metaphor, which declares social unity and social hierarchy to be a key to understand the society, the work (Kukathas 2011) uses the metaphor of archipelago of diverse communities, existing in the sea of "mutual tolerance. This liberal archipelago represents a community of communities, not generated and not governed by any single authority, although it is a variety of a structure where the authorities act in conformity with the laws, which, by themselves are out of any control by a single authority".

A free society is supposed to have availability of multitude of authorities, independent of each other, respect of some authorities to independence of others, unwillingness to meddle in their business, while the existence of authorities is supported by readiness of citizens to submit to them. In this way, an authority is understood as the force to which one appeals with the purpose to settle conflicts, when it has been impossible to settle them by another means, e.g. agreements without mediators. Liberalism supposes that no one authority possesses an absolute understanding of matters being the cause 
of conflicts, but this authority, nevertheless, is needed for the purpose to settle conflicts (Kukathas 2011).

So, if we proceed from the principles of free society, the formation of an intersubjective system to regulate a problem situation must come to a creation (on the basis of self-organization) of a community of communities (a composite holon), representing an association of actors (together with resources in their possession), who possess common understanding of what kind of matters, within the framework of this association, shall be regulated jointly, and what kind of matters shall be settled by each actor independently. In order to legalize these accords, actors enter into agreements which share zones of responsibility for adopted decisions. For settlements of eventual conflicts, one or several actors are endowed of lowrarchy-based authority and resources (Ackoff 2009), i.e. the "higher" elements of intersubjective system receive authority and resources from the "lower" elements. But determining processes in the intersubjective system are the processes of a non-violent communication of actors, based (according to Habermas) on "solidarity, orienting common will" (New Philosophical Encyclopedia 2010). Strictly speaking, there is no upper or lower level in such a system; there is no division for levels at all, "there are only interactive key points of responsibility" (Cloke and Goldsmith 2004).

Bureaucratic systems are built on an opposite assumption, supposing that the people are not willing or unable to take responsibility upon them for consequences of their activity. Then, a strict control and hierarchical order are pushed on foreground, requiring that each decision would be repeatedly rechecked by managers of various levels. But such a "guardianship" generates exactly the situation, when "an important part of personnel is not opposed to be ruled by authoritarian managers and are ready to act in the role of unwise children in exchange for a reduced liability" (Cloke and Goldsmith 2004). Intersubjectibe systems, on the contrary, are aimed to increase shared liability for common success of the community.

\subsection{Actualization of Actors' Personal Knowledge}

Actors aspire to understand the problem situation, i.e. to catch its sense; with all that, each of them has its pre-understanding (Modern Philosophical Dictionary 1998; The World Encyclopedia 2001; Vittikh 2005). Both there is no cognition without knowledge, and there is no understanding without preceded pre-understanding. Preunderstanding, according to Heidegger, makes subjectively painted the understanding, connected with interpretation of any text (Shulga 2004). Pre-understanding, expressing objective world of the man, situated in its "field of vision", as a matter of fact, represents the aggregate of a priori personal knowledge of the actor (Vittikh 2007), on the basis of which he comprehends the sense of the formed situation. In other words, it is just personal knowledge that is actualized (turned out to be mobilized) in the first instance, i.e. the knowledge which the actor acquired before appearance of the problem situation. We may divide this knowledge into verified knowledge and axiological knowledge (Vittikh 2009c). Scientific researches which are conducted in natural sciences (physics, chemistry, biology etc), have as its results some knowledge, the truth of which is not only alleged, but proved, explained; at the same time, the knowledge's content doesn't 
depend on researchers, and that allows to refer it to the category of objective one. Let us call it verified knowledge.

Side by side with it, an important part of knowledge, acquired, for example, in technical sciences, is applicable only in any specific situations of life and bears a subjective character, though it has a big practical value being intended to satisfy human needs. Such knowledge may be defined as axiological knowledge, accentuating its values in contrast to the truth of verified scientific knowledge. We may also speak about consistency, feasibility, interpretation ability of axiological knowledge, etc.

In other words, classical scientific verified knowledge is not considered to be unique form of knowledge which, in accordance with contemporary conceptions, is determined as information being of social importance and recognized by certain social subjects and by society in whole to be exactly in the capacity of knowledge (The World Encyclopedia 2001).

People began to apply axiological knowledge long before they started to acquire verified knowledge. Primitive man was able to orient him-self on the ground, he knew the habits of animals, distinguished the properties of plants, had an idea about human anatomy, etc. All this knowledge was of a big practical value for him. And only somewhere in the 6th century B.C., when the thinkers of Ancient Greece divided the "subject" and the "object", first notions of verified knowledge and its truth appeared.

Since that, axiological and verified components of the knowledge have been developing simultaneously and not independently but complementing one another. So, for example, creation of fundamentals of mechanics by I. Newton in 17th century was preceded by accumulation of large amount of axiological knowledge, with the aid of which complex building structures were erected, ships and armaments were created etc. On the other hand, mechanics laid grounds for the origin of axiological knowledge, important for the people, practical appliance of which allows, up to now, satisfy more and more increasing needs of the humankind.

It is clear that each individual is able to acquire on his own a restricted amount of personal (both axiological and verified) knowledge. Therefore, colliding with indeterminacy of any formed situation, the man tries to use personal knowledge of other people, each of them having his own pre-understanding of situation. For example, solution of any problem of industrial manufacture may require the knowledge of a process engineer, a power engineer, a financier, an ecologist and many other specialists, examining the problem situation from the positions of their personal professional knowledge. The question is in what extent this knowledge is accessible for surrounding people and how efficiently it is used.

If a personal knowledge is "attached" to its possessor, then its use becomes dependent on "caprices" of an individual right up to refusal to apply it in the processes of decision-making. At the same time, it is very important, in the stage of preunderstanding, to enable each actor to get acquainted with the points of view of his colleagues, and that can be resulted, among any others consequences, in transformation of his proper views on the problem situation. Then, it is necessary "to extract from the subject" this knowledge, to formalize it and to present in a convenient form to the interested actors. These problems are successfully solved by means of ontologie 0073 (Smirnov 2012). In other words, actualization of personal knowledge of actors can 
be implemented by elaboration and placement of their personal ontology in computer networks.

\subsection{Intersubjective Agreements of Actors}

In order to master the situation with concerted efforts, heterogeneous actors must come to an agreement on decision-making principles and on some common "rules of the game" shared by everyone.

Therefore, the theory of intersubjective management, equally with personal knowledge of actors, represented in the form of ontologies, contains intersubjective knowledge, being the result of the actors' agreements within the framework of semantic, empiric, logic, operational and normative intersubjectivities (Huebner 1996) (see section 1.6). This knowledge, as well, is proposed to represent with the aid of ontologies: ontologies of corporative culture, of decision-making, of activity, of facts, normative and legal ontology (Vittikh et al. 2012a).

Ontology of corporative culture. Intersubjective theory comprises a restricted multitude of actors who must be unified by a common culture, which is frequently named as corporative, since, otherwise, attainment of mutual understanding is extremely difficult (or impossible at all) even in the case when indeterminacy of situation is exceedingly small and it could be settled at the level of local mutual understanding without use of any global structures (for example, normative and legal acts). Semantic intersubjectivity, in this case, involves a common representation and consent of actors in relation to the corporation's mission, its value priorities and rules of corporative behavior. All that aggregate of appropriate notions and relations among them can be expressed by means of ontology of corporative culture, allowing the partners to conduct a dialogue "in the same language", understanding each other quickly enough.

Ontology of decision-making. Logical intersubjectivity is associated with achievement of consent between the actors in the logics of decision-making. It is far to mean that we have in mind classical logics based on the sequence of "notion-judgmentconclusion", since in the hermeneutical logics, for example, it is just the conclusion that becomes primary. The conclusion appears when "indeterminacy, wherein the man discovers himself, requires an immediate decision" (Mikhaylov 2003). Logics of decision-making may proceed from democratic or, otherwise, from autocratic principles, etc. Furthermore, one can use in a real life not one but a multitude of logics (Shuman 2004). Description of this aggregate in the form on notions and relations will represent ontology of decision-making which must be shared by all the actors who take part in regulating a problem situation.

Ontology of activity. Operational intersubjectivity proceeds from interpretation ability of actions patterns. At the same time, it is supposed that a certain succession of actions (of technologies) is based on this pattern by an obligatorily accessible manner. Separate elements of such technology and their succession, constituting this pattern, are understood by everyone in a unique manner and can be reproduced in the same form. In essence, the question is about "admissible technologies" of activity, which may be used on the basis of a common consent (consensus). The aggregate of these kinds of activity may be represented in the form of ontology of activity including 
description of technologies with specification of responsibility for their implementation (as it was done, for example, in the work Vittikh et al. 2009a). Ontology of activity, thus, will not only provide with its regulation, but contribute to the rise of level of actors' personal responsibility.

Ontology of facts. Empirical intersubjectivity assumes to be necessary the wellfounded nature of judgments by facts which must be recognized by all actors who are in the problem situation, as far as, otherwise, mutual understanding becomes problematic. Therefore, elaboration of the ontology of facts becomes significant; these facts must be classified by degree of their trustworthiness: from rumors generating doubts up to precedents allowing using the cases which took place in the past, to justify the decisions one is making in the present time. With all that, ontology doesn't include, of course, the facts that have taken place, but, in opinion of actors, mustn't be taken into consideration (by any causes).

Normative and legal ontology. Normative intersubjectivity assumes generally accepted character of norms and rules of behavior or appraisal, in conformity of which can be built a normative and legal ontology, containing an interconnected complex of laws, orders, standards, agreements and other normative regulatory documents which secure regulation of relationships of actors at a certain level of indeterminacy of the situation. If however the degree of indeterminacy of situation rises, exceeding an allowable threshold, new rules of actors' interaction are elaborated, which transform normative and legal ontology, and it means that a permanent monitoring of normative and legal framework must be arranged. This kind of ontologies, implemented in the form of computerized normative and legal framework of knowledge were used, particularly, at elaboration of regional system of provision of governmental and municipal services in electronic forms to the population of the Samara region, Russia (Vittikh et al. 2009b).

It is to note that, to attain actors' intersubjective agreements, elaboration and appliance of appropriate systems of communicative actions' support is required (Vittikh et al. 2012b).

\subsection{Attainment of Actors' Mutual Understanding}

On the basis of the elaborated theory of intersubjective management, including personal and intersubjective knowledge in the form of ontologies, actors build in common an Ontological Model of Situation (OMS), with the help of which they comprehend the sense of the formed problem situation (Vittikh 2009b). In contrast to ontologies of a theory, containing abstract notions and relationships between them, OMS describes specific objects of the real world. For example, there are some notions in the railway traffic which are "general" and not bound to an actual situation: route, train, carriage, stage between stations, station, points, engine-driver, traffic controller, etc., but the relationships between them are: relationship of inclusion (carriages form a train), relationship of place (train is on a station or on a stage), relationship of action (traffic controller changes the points position, engine-driver drives the train), etc. (Vittikh 2005; Vittikh et al. 2003). At the same time, in OMS, the question is about a specific train which is composed of 8 carriages and which follows the route from London to Cambridge, while the problem situation consists in the fact that, in connection with an 
increase of passengers flow, a demand occurred to introduce an additional high-speed express train and it should be resulted in variation of train schedule on the division between London and Cambridge. OMS includes the description of the railway network composed of stations, stages, trains, engine-drivers with their attributes, as well as conditions and restrictions at schedule forming: traffic safety intervals, availability of unoccupied train crews, priorities and speeds of train traffic, availability of side tracks at the stations to set there the trains under overtaking, etc.

The example, given in Vittikh et al. (2003), assumes that, on the London-Cambridge division, there are three trains running which depart from London with a five minutes interval. The added express train should run with a higher speed, but it results in "a deadlock situation", consisting in the fact that the express train can overtake usual local trains on stages between stations, where there is only one main road in the bound direction. Thus, the problem is how to arrange the transit of this train without disturbing the traffic safety.

Safety index is in priority for the traffic controller. At the same time, the railway administration, in connection with variation of traffic schedule due to the added express train, may aspire to gain additional profits from this situation; as for engine-drivers, they aspire to have wages increase. So, OMS will include all this knowledge and data characterizing various points of view of the actors (administrators, traffic controllers, engine-drivers), their subjective understanding of the problem situation.

Nevertheless, it is far to mean that the problem is solved, since the decision-making, which is convenient for everybody, takes place under the conditions of multitude of resource restrictions (financial, technologic, power supply etc). Therefore, the OMS built by actors is a formulation of the problem but not a solution thereof. The abovestated position matches to a large degree with the views of Laurière (1991), who, speaking about solution of problems one meets in the every-day-life, had in mind rather "analysis and representation of specific situations" than the solution it-self. "To formulate a problem means first of all to understand conditions of the problem or, in other words, to find an appropriate representation". In other words, the originally elaborated OMS reflects understanding of the problem by actors, but they haven't yet attained mutual understanding as to the manner to regulate the problem situation that would be convenient for everyone.

Then, the actors begin to conduct experiences with $O M S$, defending their positions, on the one hand, and taking in account the interests of their colleagues and valuable benchmarks of groups, from the other hand. There is a step-by-step OMS transformation, in result of which OMS is elaborated and this OMS is shared by all the actors wherethe mutual understanding of heterogeneous actor is attained at last (Vittikh 2012b). It is important to have in mind that the actors' preferences depend on the context and character of interactions among them, and the preferences scales are being formed in the process on negotiations themselves, not being rigidly specified a priori (Sapir 2001). This circumstance, restricting the appliance of classical mathematical methods when experimenting with OMS, results in necessity to look for other methods and tools among which are multi-agent models and technologies (Skobelev 2010; Vittikh and Skobele 2003).

It should be noted that a general scheme of such ontological modeling was suggested and discussed in details in the work (Smirnov 2012). 


\subsection{Decision-Making}

The decision-making to regulate a problem situation on the basis of the theory of intersubjective management is directly connected with attainment of actors' mutual understanding and consensus, i.e. their common consent in the disputable issue, obtained by way of negotiations, due to convergence of the actors' positions. More precisely, consensus is not a unanimity, it doesn't mean that "everybody votes pro", it means only that "nobody votes contra" (Ackoff 2009). Consensus is being formed gradually, in proportion as OMS under transformation comes nearer to the model shared by all the actors. And, if OMS doesn't arrange even one of actors, the decision is not made.

Such an approach may be resulted in undesirable delays in decision-making under the conflict of interests' conditions of the actors. However, if to stake on their solidarity, then the way out can be found; it is necessary, for this purpose, to arrange monitoring of the speed of the problem situation's development. When actors will begin to understand that the time reserves of decision-making will have expired in the nearest future, it will stimulate them to go on mutual concessions, to look for compromises. And it means that the number of OMS transformations, necessary to attain consensus, will self-regulate, providing the ability to control in real time.

Alternative is the traditional "majority principle": not to waste time for a long term negotiations and for convergence of positions, but to make decision by a simple voting. In this event, time could be saved indeed, but there will be no guaranty of decision's quality, since a part of actors having weighty arguments will not agree with the chosen way to regulate the situation. "As is well known since the times of Condorcet, the majority rule does not guarantee the expression of preferences of society, i.e. it can lead to irrational results... It is noteworthy that the classical decision theory leads to a tense confrontation of rationality and irrationality, but leaves everything as is" (Luhmann 2000).

In fact, we are so accustomed, indeed, to do a choice according to the principle of "majority", that, usually, we don't think about "minority" and what this minority is expected to be in result of the decision made (not in the minority's favor). At the same time, history brings us many lessons of negative consequences derived from the dictates by majority, resulting in infringement of rights and freedoms of a part of people. Therefore, the theory of intersubjective management is being built exactly consensusbased, presupposing a non-violent decision-making and, in this sense, meeting the principles of free society.

\section{Conclusion}

These last years, within the framework of the global idea to modernize our society, we see development of lines of activity and implementation of appropriate programs connected with organization and perfection of the process of management: electronic democracy, electronic government, private-state partnership, public-state partnership, information society development, etc. They are aimed to expand participation of citizen, business and social organizations in lawmaking, to make adopt socially significant decisions by authority, to perform the processes of State, municipal and corporative 
governance. And what's more, following traditional conceptions, the solution of these problems is made on the basis of the principles of classical bureaucracy with its rigid hierarchy of power, functional specialization, procedures regulations, disregard of personal qualities of people, etc. This "mechanistic nature" and "depersonalization" of bureaucratic structures, which ensured their success in the industrial epoch, have begun to be nowadays a hindrance for social, economical and humanitarian development, since the world has become open and dynamic, the man started to realize him-self more and more free therein, communication has become a productive force, social self-organization has got development. In these conditions, any redecorating of bureaucratic machine which doesn't touch its fundamentals cannot ensure any proper efficiency of management in the present-day society. A change of the very paradigm of management is required.

Exactly for this purpose, this work proposes the principles of construction of the theory of intersubjective management, based on postnonclassical scientific rationality and on concept of free society, wherein the stake is made on non-violent means of decision-making oriented towards attainment of mutual understanding and consensus. Yet it is only an introduction to the theory, and not the theory itself, but its publication is conditioned by a matured need to draw attention to the above-named problem and to expand the circle of scientists and professionals involved in search of the solution. Of course, the theory of intersubjective management is a certain idealization (as, however, any other theory, including the "ideal bureaucracy"), but, over the years, it will become more and more in line with the realities of the future information society.

Open Access This article is distributed under the terms of the Creative Commons Attribution License which permits any use, distribution, and reproduction in any medium, provided the original author(s) and the source are credited.

\section{References}

Ackoff RL (2009) Beyond socialism and capitalism: developing society. Probl Manag Soc Syst 1(1):112140

Chaykovsky YV (1993) On the general theory of evolution. Way Int Philos Mag 1(4):101-141

Cloke K, Goldsmith J (2004) The end of management and the rise of organizational democracy. Piter, SPb Dictionary of Philosophical Terms (2004) Infra-M, Moscow

Furs V (2001) Paradigm of critical theory in contemporary philosophy: attempt of explication. Logos 2:46-75

Habermas J (2006) Moral consciousness and communicative action. Nauka, SPb

Hartmann N (1997) Zur Grundlegung der 1941. Ontologie. Reference is given acc. to philosophical encyclopedic dictionary. INFRA-M, Moscow, p 416

Heidegger M (2003) Being and time. Folio, Kharkov

Huebner K (1996) The truth of the myth. Respublika, Moscow

Johnson RA, Kast FE, Rosenzweig JE (1967) The theory and management of systems, 2nd edn. McGrawHill, New York, (translation from English, Moscow: Sovetskoye Radio)

Koestler A (1989) The ghost in the machine. Arcana books, London

Kokhanovsky VP, Leshkevich TG, Matyash TP, Fatkhi TB (2004) Fundamentals of philosophy of science. Phoenix, Rostov, Don

Kukathas C (2011) The liberal archipelago: a theory of diversity and freedom. Mysl, Moscow

Kueppers G (1999) Self-organisation- the emergence of order. From local interactions to global structures. SEIN Project Paper No. 2. University of Bielefeld, Bielefeld 
Laurière J-L (1991) Systems of artificial intelligence. Mir, Moscow

Losev AF (1969) History of ancient aesthetics. Sophists. Socrates. Plato. Iskusstvo, Moscow

Loskutnikova VM (2011) Habermas and Luhmann: two approaches to researches of communication in the contemporary society. Open Interdisciplinary Magazine "Humanitarian Informatics", Issue 1, Publishing House of Tomsk University, Tomsk. http://huminf.tsu.ru/e-jurnal/magazine/2/losk.htm

Luhmann N (2000) Decisions in information society. Problems of theoretical sociology, issue 3. Publishing House of SPb's State University, SPb

Merrill GH (2003) The Babylon project: towards an extensible text-mining platform. IEEE IT Pro, MarchApril 2003, IEEE Computer Society

Mikhaylov IA (2003) Hermeneutical logics of G. Spaeth and G. Lipps. Gustav spaeth's creative heritage in the context of philosophical problem of historical and cultural consciousness formation (Interdisciplinary Aspect). Publishing House of Tomsk University, Tomsk, pp 114-123

Modern Philosophical Dictionary (1998) London, Frankfurt am Mein, Paris, Luxembourg, Moscow, Minsk "PANPRINT"

New Philosophical Encyclopedia (in four volumes) (2010) Mysl, Moscow

Novikov AM, Novikov DA (2007) Methodology. SINTEK, Moscow

Philosophy (2003) Textbook for Higher Educational Institutions. Phoenix, Rostov/Don

Philosophy (2004) Gardariki, Moscow

Prigozhin I, Stengers I (1986) Order out of chaos. (Man's New Dialogue with Nature). Progress, Moscow

Sapir J (2001) On economic theory of heterogeneous systems (experience in research of decentralized economy). State University, Higher School of Economics, Moscow

Shepard HA (1965) Changing relationships in organizations. In: March JG (ed) Handbook of organizations. Rand McNally, Chicago, III

Shulga EN (2004) Problems of pre-understanding in hermeneutics, phenomenology, sociology. IF RAN, Moscow

Shuman AN (2004) Contemporary logics: theory and practice. Ekonompress, Minsic

Simon H (1972) The sciences of the artificial. Mir, Moscow

Skobelev PO (2010) Multi-agent technologies for industrial applications: to 20 anniversary of Samara Scientific School of multi-agent systems. Mekhatronika Avtomatizatsia Upravlenie 12:33-46

Smirnov SV (2012) Ontological modeling in situational management. Ontol Proektirovaniya 2(4):16-24

Social Philosophy: Dictionary (2006) Akademichesky proekt, Moscow; Delovaya kniga, Yekaterinburg

Solovieva EV (2009) The concepts of "Public" and "Communicative Action" of Jurgen Habermas as a tool for analysis of social partnership. Bull Nizhny Novgorod's N.I. Lobachevsky Univ (series "Social Sciences") 1:62-66

Sorokin PA (2006) Social and cultural dynamics. Astrel, Moscow

Spencer H (1997) Synthetic philosophy: translation from english. Nika-Centre, Kiev

Stepin VS, Gorokhov VG, Rozov MA (1996) Philosophy of science and engineering. Gardariki, Moscow

The World Encyclopedia (2001) Philosophy. AST, Moscow; Harvest, Sovremenny Literator, Minsic (2001)

Vikhansky OS, Naumov AI (1999) Management: textbook, 3d ed. Gardariki, Moscow

Vittikh VA (2002) Integrity of complex systems. Problems of controlling and modeling in complex systems. In: Proceedings of IV international conference. Samara Scientific Centre of Russian Academy of Sciences, Samara, pp 48-58

Vittikh VA (2005) Control process in socio-technical systems. In: Proceedings of VII international conference. Samara Scientific Centre of Russian Academy of Sciences, Samara, pp 32-42

Vittikh VA (2007) Knowledge personalization. Problems of controlling and modeling in complex systems. In: Proceedings of IX international conference. Samara Scientific Centre of Russian Academy of Sciences, Samara, pp 441-446

Vittikh VA (2009a) Paradigm of limited rationality of decision-making-1. Bull Samara State Tech Univ (series “Technical Sciences") 3(25):22-31

Vittikh VA (2009b) Ontological models of situations in the processes of collegial decision-making. Problems of controlling and modeling in complex systems. In: Proceedings of XI international conference. Samara Scientific Centre of Russian Academy of Sciences, Samara, pp 405-410

Vittikh VA (2009c) Axiological and verified scientific knowledge. Problems of controlling and modeling in complex systems. In: Proceedings of XI international conference. Samara Scientific Centre of Russian Academy of Sciences, Samara, pp 449-454

Vittikh VA (2010) Organization of complex systems. Samara Scientific Centre of Russian Academy of Sciences, Samara 
Vittikh VA (2011) Cognitive science for developing systems. Mekhatronika Avtomatizatsia Upravlenie 10:45-49

Vittikh VA (2012a) Intersubjective systems as the entities of postnonclassical science. Mekhatronika Avtomatizatsia Upravlenie 1:53-55

Vittikh VA (2012b) Situational management from the positions of postnonclassical science. Ontol Des 2(4):C. 7-C. 15

Vittikh VA, Skobelev PO (2003) Multi-agent models of interaction for networking needs and opportunities in open systems. Avtomatika I Telemekhanika 1:177-185

Vittikh VA, Skobelev PO, Shamashov MA, Shveykin PK (2003) Multi-agent system for decision-making support at schedules formation and at railway traffic controlling. In: Proceedings of V international conference. Samara Scientific Centre of Russian Academy of Sciences, Samara, pp 340-346

Vittikh VA, Sitnikov PV, Smyrnov SV (2009a) Ontological approach to construction of information and logic models in the processes of control by social systems. Bull Comput Inf Technol 15:45-53

Vittikh VA, Volkhontsev DV, Gritsenko EA, Svetkina GD, Skobelev PO, Surnin OL (2009b) Regional system of provision of state and municipal services to the citizens in electronic form with appliance of integrated knowledge base and multi-agent technologies in the social sphere of Samara region

Vittikh VA, Ignatyev MV, Smirnov SV (2012a) Ontology in the intersubjective theories. Mekhatronika Avtomatizatsia Upravlenie 5:69-70

Vittikh VA, Ignatyev MV, Smirnov SV (2012b) Elaboration of communication actions support systems. In: Problems of Controlling and Modeling in Complex Systems: Proceedings of XIV International Conference. Samara Scientific Centre of Russian Academy of Sciences, Samara, pp 125-130

Zotov AF (2010) Contemporary occidental philosophy. Prospekt, Moscow

Zub AT (2010) Making management decisions. Theory and practice: a training manual. ID, Moscow: INFRA-M "FORUM" 